\title{
PRELIMINARY INVESTIGATION ON THE USE OF THE Q-SWITCHED ND:YAG LASER TO CLEAN CORROSION PRODUCTS ON METALLIC EMBROIDERY TEXTILE MUSEUM OBJECTS
}

Bojana Radojkovića ${ }^{\text {* }}$, Slavica Ristića ${ }^{\mathrm{a}}$, Suzana Polić ${ }^{\mathrm{b}}$, Radmila Jančić-Heinemann ${ }^{\mathrm{c}}$, Danijelka Radovanovićd,

${ }^{a}$ Institute Gosa, Milana Rakića 35, Belgrade, Serbia, bojana.radojkovic@institutgosa.rs, slavica.ristic@institutgosa.rs

${ }^{\mathrm{b}}$ Central institute for conservation, Terazije 26, Belgrade, Serbia, suzanapolicradovanovic@gmail.com

${ }^{c}$ Faculty of Technology and Metallurgy, Karnegijeva 4, Belgrade, Serbia, $\underline{\text { radica@tmf.bg.ac.rs }}$

${ }^{\mathrm{d}}$ Ethnographic Museum in Belgrade, Studentski trg 13, Belgrade, Serbia, rada.n@sezampro.rs

Corresponding Author:

Bojana Radojković, Institute Gosa, Milana Rakića 35, Belgrade, Serbia, bojana.radojkovic@institutgosa.rs tel.: +381648389828 


\title{
PRELIMINARY INVESTIGATION ON THE USE OF THE Q-SWITCHED ND:YAG LASER TO CLEAN CORROSION PRODUCTS ON METALLIC EMBROIDERY TEXTILE MUSEUM OBJECTS
}

\begin{abstract}
The classic methods of cleaning oldfashioned textile museum objects with metallic threads often do not yield the expected results. The use of laser in the conservation of these objects plays an important role as very efficient and ecologically friendly technique. Conservation and restoration of historical exhibits with metal-textile combinations is becoming ever more complex due to a huge variety of damaging factors. The paper presents the results of the corrosion laser cleaning effects on ethnographic textile with metallic threads from the holdings of the Ethnographic Museum in Belgrade, using Nd:YAG laser. Testing of the cleaning effects was performed by optical and scanning electron microscopy. Chemical analysis of metal threads is made by EDX and XRD analysis. Parameters for successful and safe cleaning of corrosion products on metallic threads were determined.
\end{abstract}

Key words: laser cleaning; corrosion; metal threads; phosphine; SEM; XRD. 


\section{Research aims}

The paper presents results of research on laser application for corroded metal thread cleaning on the embroidered textile artworks. The aim of this work is the determination of optimum laser parameters for successful cleaning of the corroded metal threads without any damage of the metal strips and underlying cotton, on the sample of female shirt from the museum collection. The different laser wavelengths and fluencies are used in the dry and wet experimental condition. Morphological and chemical modifications in laser cleaning zones are investigated by optical and scanning electron microscopes, energy-dispersive (EDX) and X-ray Powder Diffraction (XRD) spectroscopy. Obtained results confirmed that for these samples, which are a combination of two different materials, silvered copper strip and cotton, application of the Nd-YAG lasers with appropriated parameters is the more effective cleaning method related to classical ones. The evaluation of the tested areas can give important experience and further laser cleaning of shirt will be based on obtained results.

\section{Introduction}

The deterioration of museum objects depends on the nature and the environment surrounding the object. Environmental factors that affect artworks are humidity, temperature, light, pollutants, microorganisms and insects. These factors induce structural damage, modification of materials, corrosion and 
agglomeration of pollutants and microorganisms on the cultural heritage artworks, stored in museum depot or exhibited in galleries. This especially affects the samples such as textile embroidered with metal threads.

The numerous literature describes the classic methods and problems accompanying their implementation in cleaning and protection of metallic threads in textile museum objects [1,2]. Traditional cleaning methodologies usually employ a mechanical removal or chemical reactions, or a combination of these two methods [3]. The ideal cleaning treatment should remove the tarnished layer without affecting the underlying metal surface and also the fabric.

Laser cleaning is one of the most ecological methods in conservation and restoration of cultural heritage in comparison with classical ones, due to the fact that the only wastes generated are the impurities ejected from the surface of artworks.

The lasers are sources of radiation with easily controlled energy, which can be directed at an object in order to controllably and selectively remove undesired layers from surfaces, with high accuracy. The results of laser cleaning depend on a number of parameters related to laser and object surface characteristics. The most complicated is the use of lasers in cleaning items that have a multi component structure $[4,5,6,7]$.

Laser cleaning is an effective cleaning technique of metal corrosion layers since it provides a high degree of control that allows fragile objects with a considerable amount of surface detail and different materials to be successfully and safely cleaned. There are many investigations of lasers applications in 
cleaning glass [8], ceramics [9], stone [10, 11], easel and wall painting [11,12], metal objects $[11,13,14,15]$, textile $[5,6,7,16,17,18]$, other organic and biological samples etc. For every type of laser-material interaction, determination of the most appropriate methodology for successful laser cleaning contains optimization of the laser parameters in accordance with material properties. Also, a good knowledge about the ablation mechanism that occurs is required $[1,16,17,19]$.

$\mathrm{Nd}$ :YAG lasers are highly effective in conservation of artworks, as is confirmed with numerous tests. Siano et al. [11] presents the state of the art, new innovation and new perspective application of the Nd:YAG lasers in cleaning of different artworks. Cleaning of dirty, corroded surfaces of two copper alloys archaeological objects with Nd:YAG laser, wavelength of $1064 \mathrm{~nm}$ and laser pulse of $120 \mathrm{~ns}$, is presented in [13]. Degrigny et al. [1] analysed the copper thread samples, cleaning with Q-switched Nd:YAG lasers performed with laser wavelength of $532 \mathrm{~nm}$.

The most complicated implementation of laser in cleaning the objects with multi-component composition such as, metal and textile combination is given in $[1,5,6,7,19,20]$. The Nd-YAG laser that was used in this study has twice as much energy in comparison to the laser used in [1] and can achieve higher fluences. The laser cleaning threads in the museum textile, reported in $[5,6,7,19]$ was made of silver ribbon wrapped around a bunch of silk fibres. Elnaggar et. al [6] were investigated using picosecond laser scanning pulses $(1064 \mathrm{~nm})$ for the removal of tarnish from the surface of silvered metal threads. Unlike previous research, in the study whose results are analysed, the sample is made of cotton embroidered with 
silver-coated copper ribbon wrapped around a bunch of cotton fibres. Also, the nanosecond pulse regime was used for irradiation. Although there are certain published results, this domain has not been sufficiently researched because every object is a problem that requires study and comprehensive research before cleaning is attempted.

This paper shows the results of research conducted with the aim of determining optimum parameters in the cleaning process of the corrosion product on a female shirt from Donja Brnjica, Kosovo and Metohija, Serbia. Shirt is handmade, dated early twenty century and represents part of Serbian, national wedding costume. A very small number of similar specimens are preserved.

The results obtained by using the Nd:YAG laser, was studied with: optical microscope and scanning electron microscope SEM with EDX. XRD analysis is used for determination of crystalline phase and chemical composition of corrosion products.

\section{Degradation of embroidered textile artworks}

In the rich collection of embroidered textile objects the various metal threads types can be met: metal strips or wires made of copper or zinc (silvercoated or gilded), strips wound around a silk or cotton yarn, spiral wires, gilt leathers strip wound around a silk yarn, etc. The thickness of precious metal coating is measured in microns [21]. The fabrics of the embroidered handcraft objects are cotton, linen, hemp, wool or their combinations. 
The corrosion processes that occur under the external, mechanical, chemical and biological influences take place on the phase boundaries. They are chemical, anodic and cathodic reactions and adsorption processes, resulting in general and local oxidation of the material [22]. The microorganisms such as fungi, algae and bacteria cause biological corrosion and damages of organic fibers, too [23].

Corrosion products, generated in reaction of copper and its alloys with environment, are commonly copper oxides, basic copper sulphates, copper chloride and basic copper carbonates. Some corrosion products protect the underlying metal from further corrosion. But, copper chloride cleaning is necessary because of artworks stabilization, and also due to the further potential conservation procedures.

Silver objects can form a thin patina, depending on the aggressiveness of the environment. [24]. Silver is specifically attacked by sulphide gases. Silver sulphide usually appears as a black layer of corrosion on silver museum objects and this kind of corrosion is known as tarnish.

\section{Sample description}

The Ethnographic Museum in Belgrade, in its depots, keeps a great number of textile objects which are part of the world cultural heritage $[4,5]$. Safekeeping of these exhibits must be fully comply with the principles of preventive protection. For that purpose the Ethnographic Museum in Belgrade vests 
significant efforts to provide the necessary conditions for preventive protection. In spite of all, in the early nineties of the past century, changes were observed on several objects with metallic thread embroidery. The thread darkened and became brittle and some threads began crumbling on touch. With time, this phenomenon became visible on a growing number of exhibits. Some measures have been taken in the last fifteen years to solve this problem. Previous research showed that phosphine, used as fumigant, could cause the most of these damages.

The studied shirt, dated from 1914, is made of cotton embroidered with cotton thread and silver-coated copper thread on the sleeves and in the centre at the hem of the shirt back side. The photos of the shirt, are shown in fig 1.( $a$ and $b$ were recorded in 1964 and c,d,e in 2013) Silver-coated copper sequins were fixed with glass beads using a cotton thread. It is decorated as well with glass beads, strung on a cotton thread (Fig. 1b). Parts with the metallic thread embroidery are sewn between pieces of tulle. The shirt was part of the female national costume from Donja Brnjica, Kosovo and Metohija, Serbia [4]. 

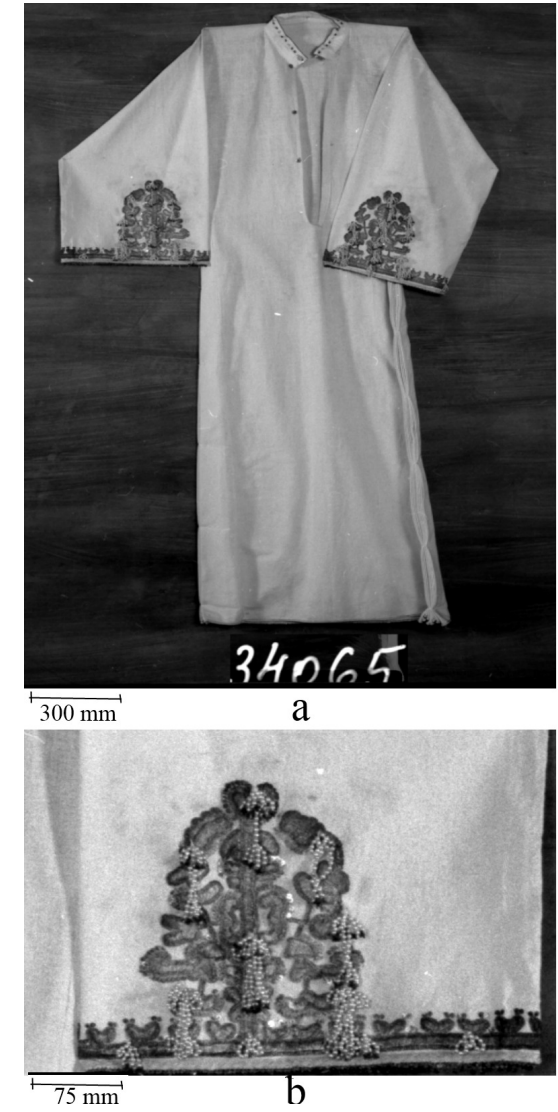

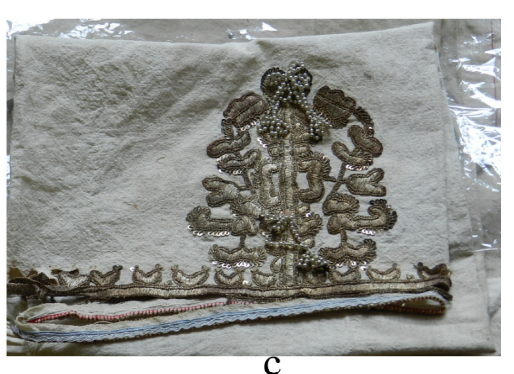

C

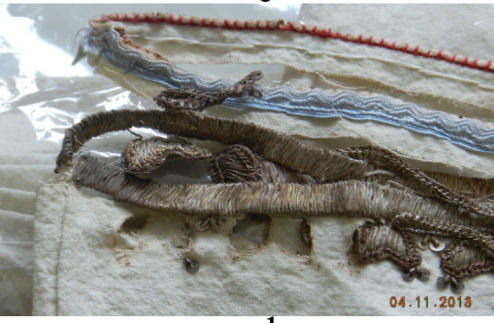

d

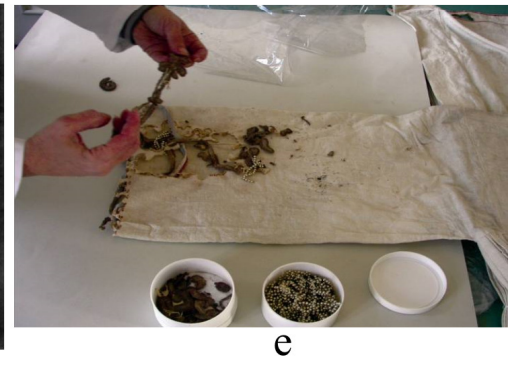

Fig. 1 The shirt, Donja Brnjica, Kosovo and Metohija, Serbia photographed in a,b) 1964 and c,d,e) 2013

Donja Brnjica is a village five kilometers north of Priština (Fig 2). As in thorough Serbian traditional culture, so on Kosovo and Metohija, embroidery is a very important method of textile items decorating. Centuries nurturing and applying of embroidery decoration method has, in the beginning of twentieth century, led to a production of wealth of ornaments. Also with industrialization which at that time was took place in Serbian society, embroidery techniques has been improved. Wedding shirts are specially decorated with gilded and silver threads. 


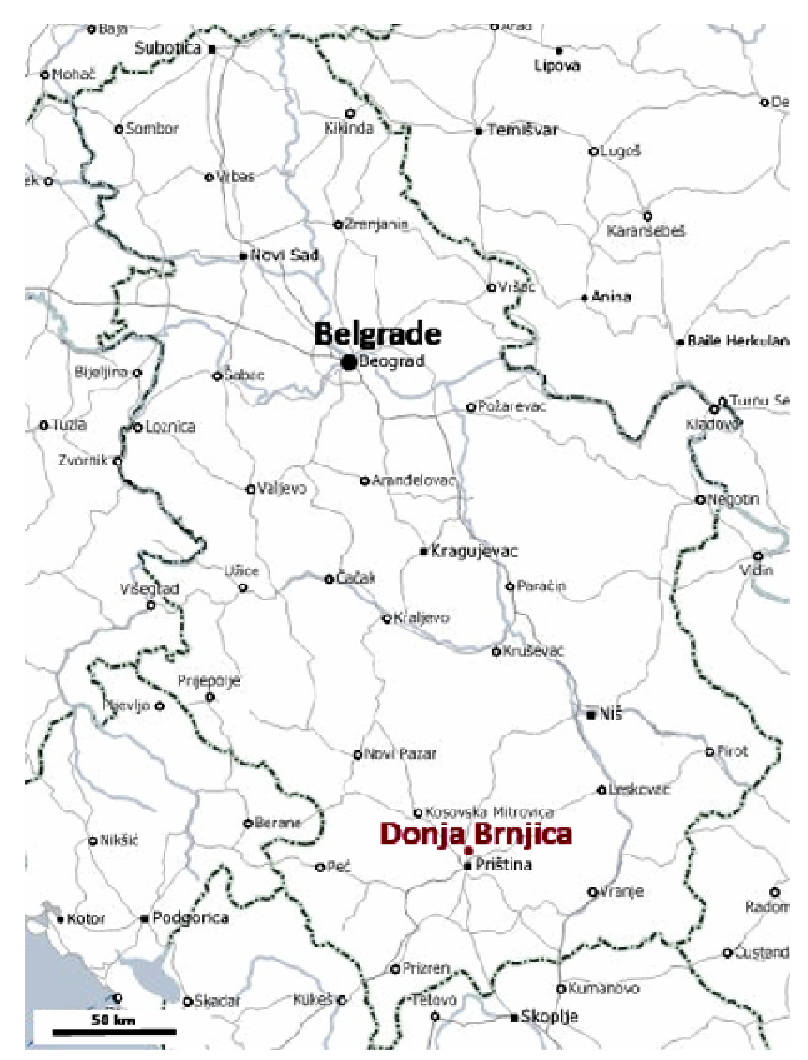

Fig. 2 Donja Brnjica on the map of Serbia

The shirt embroidery was in excellent condition at the time of purchase (1964) (Fig. 1a and 1b). The shirt was placed in storeroom treated with different pesticides. Mothballs based on paradihlorbenzol were placed in textiles depots from 1968 to 1984, after the regular, annual air ventilation. Since 1984, the pest control of the depots was done by usage of fumigants as are Nuvan 7 and phosphine. Last treatment of museum space by phosphine was conducted in 1999. After that protection against pests was carried out by the herbal strewing solution (tansy). During the years defects that are the result of corrosion have appeared. Corrosion processes have slowly led to the destruction of embroidery parts of the shirt, and corrosion products are ruining the aesthetic appearance of the shirt. 
Visual inspection of the sample shows damages that may be the results influenced by several types of corrosion.

Tests of corrosion causes began in 2000. The measurement on metal threads showed that the $\mathrm{pH}=3.5$, which means that the reaction was substantially acidic. Testing samples of damaged silver by emission spectroscopy showed great presence of phosphorus (9\%).

Metal phosphide tablets, which are used in depot fumigation, develop phosphine. They contain a certain amount of ammonium carbonate, ammonium bicarbonate, urea and paraffin that control the rate of extraction of phosphine and prevent its ignition. In the atmosphere, which has higher oxygen content, phosphine tends to move in a stable form-phosphoric acid. Phosphine reacts with precious metals and causes corrosion. With temperature and humidity increases, the velocity of reaction increases, too."

Cleaning of the metallic thread on the shirt was performed by applying a classic method: it was treated with a $75 \%$ aqueous solution of phosphoric acid $\left(\mathrm{H}_{3} \mathrm{PO}_{4}\right)$. After washing with distilled water, neutralization is carried out in a sodium bicarbonate, $1 \%$ aqueous solution, and again rinsed with distilled water. Some parts of embroidery were protected with paraloid B82. During the cleaning process, embroidery began to fall off from the fabric (Fig. 1e). Detail tests were performed in order to determine the effect of chemicals on the textile that would be used to stop the process of degradation of the metallic thread. These tests included: visual analysis of samples, determination of raw material composition, the effects of chemical treatment of samples, calculation of concentration of acid 
and neutralizer according to $\mathrm{pH}$ values, as well as testing the shrinkage and strength [4].

The preliminary protection measures, mentioned above, did not give good results. Moreover, it is obvious that the corrosion process has not been stopped. The photographs made in 2013 (Fig. 1c,d e) show the parts of the embroidery with loosen threads that are in a very poor state (Fig. 1d). The complex problem of degraded metallic thread on the museum object could not be resolved by classic methods used in the conservation process [4].

\section{Experiment}

The experiment was performed using a commercial Nd:YAG laser, Thunder Art Laser, a product of Quanta System. The laser can operate with three wavelengths, $1064 \mathrm{~nm}, 532 \mathrm{~nm}$ and $355 \mathrm{~nm}$. It operates in Q-switch mode. The duration of the pulse is $8 \mathrm{~ns}$. The repetition rate is $20 \mathrm{~Hz}$, unfocused, laser beam diameter is $10 \mathrm{~mm}$, with Gaussian distribution of energy. The energy of the laser beam can be changed towards wavelength as follows: for $1064 \mathrm{~nm}$ maximum energy to $1000 \mathrm{~mJ}$, for $532 \mathrm{~nm}$ to $550 \mathrm{~mJ}$, and for wavelength $355 \mathrm{~nm}$ to $200 \mathrm{~mJ}$. Laser has a mobile, articulated arm through which the laser beam is conducted with the aid of seven mirrors. Laser arm can approach the sample under different angles and at a different distance. 
The effect of the laser on the sample was performed under normal atmospheric conditions. The preliminary tests, performed on silvered copper plates (with different number of pulses and fluencies), have shown that the effects of corrosion cleaning are visible for the number of pulses above 100 and the laser fluence above $100 \mathrm{~mJ} / \mathrm{cm}^{2}$. The smaller number of pulses, 30 pulses required high fluence above $800 \mathrm{~mJ} / \mathrm{cm}^{2}$, which cause damage on cotton fibers. The experimental parameters for analised zones are provided in Table 1. Dry cleaning was performed on the zones 1-5, while part of the sample with zones 6-8 were wetted before irradiation. Spraying the surface with water before cleaning has been used. Wet laser cleaning was performed with an aim to get better cleaning efficiency by $1064 \mathrm{~nm}$ wavelength. The diameter of focused laser beam on sample surface was around $8.0 \mathrm{~mm}$.

Table 1. Experimental parameters

\begin{tabular}{|c|c|c|c|c|}
\hline Zone & $\begin{array}{c}\text { Fluence } \\
{\left[\mathbf{m J} / \mathbf{c m}^{2}\right]}\end{array}$ & $\begin{array}{c}\text { Wavelength } \\
{[\mathbf{n m}]}\end{array}$ & $\begin{array}{c}\text { Irradiation time } \\
[\mathbf{s}] \text { and number of pulses })\end{array}$ & Comment \\
\hline 1 & 100 & 532 & $5(100)$ & dry \\
\hline 2 & 200 & 532 & $5(100)$ & dry \\
\hline 3 & 250 & 532 & $5(100)$ & dry \\
\hline 4 & 200 & 1064 & $5(100)$ & dry \\
\hline 5 & 200 & 1064 & $15(300)$ & wet \\
\hline 6 & 200 & 1064 & $15(300)$ & wet \\
\hline 7 & 290 & 1064 & $15(300)$ & wet \\
\hline 8 & 380 & 1064 & $15(300)$ & \\
\hline
\end{tabular}


The morphology of the sample surface was recorded with USB optical microscope and scanning electronic microscope (SEM), JEOL JSM-6610LB. SEM is linked to the energy dispersion X spectrometer (EDX), INSA350, for the preliminary analysis of the chemical composition of the sample. Before SEM analysis, the sample was steamed with $20 \mathrm{~nm}$ thick layer of gold, with the aim of increasing the electrical conductivity, namely, obtaining a better quality of the picture of the sample area structure.

The samples of the embroidery fallen off the shirt were studied on a powder diffractometer PHILIPS PW 1710 with purpose to obtain as much as possible information about corrosion products.

\section{Results and discussion}

Museums around the world, for many years, have used the chemical products based on phosphine for protection against insects and rodents. The phosphine is a extremely volatile and react with metal, particularly with copper, zinc, silver and gold [25-27]. The tests conducted at the Vinča Institute in Belgrade [25] showed that the phosphine gas, used as fumigant in this museum, most probably accelerated the corrosion process on the shirt. High temperature, relative air humidity, as well as the possible presence of ammonia accelerates the reaction. The adsorbed layers of phosphine can react under certain conditions with metals, creating phosphides that further in reaction with the air turn into metal and 
phosphorus oxides. The phosphorus oxides react with humidity from the air, resulting in phosphorus acid, which, with the other acids, possibly existing in the atmosphere, can create insoluble or poorly soluble salts with metals. A particular problem is the possibility of forming of a gold (or silver) /electrolyte-phosphorous acid/copper (or zinc) compound. Then, the copper or zinc, which are electrically positive, in the anodic corrosion process, dissipates and causes crumbling of the thread.

Preservation of the artworks surface during laser cleaning is related to the selection of the optimal process parameters, the laser beam wavelength, energy density, length of the laser pulse, and the environmental conditions where the cleaning is performed. These factors directly affect the thermal and photomechanical phenomena that are associated with the interaction of laser radiation with the encrustation, corrosion layers and the base substrate.

The corrosion layers cleaning from metallic thread embroidery by laser is a complex phenomenon for which explanation is required knowledge of characteristics of laser lights and materials. It is based on several processes: absorption of laser energy within a very short period of time (several ns), melting of material in the heating layer depending on the applied energy, and ablation or evaporation of material. Depending on the fluence and quantity of absorbed energy, mechanical, expansion waves can be formed, consisting of evaporated material and ambient gas, which also rips off parts of the surface layers and discards them from the irradiated zone. The strength of the expansion wave 
increases if the sample is damp (very fast water evaporation), and thereby creates the conditions for more efficient cleaning of corrosion products.

This paper analyses the results of the irradiation effect of Nd:YAG laser beams with two wavelengths, $1064 \mathrm{~nm}$ and $532 \mathrm{~nm}$, on parts of the shirt with metallic embroidery. Fig. 3a shows a photograph of a sample, dimension approximately 50x50 mm, with zones exposed to the laser light with different fluences, wavelengths, number of pulses and quantity of moisture. Figures $3 \mathrm{~b}$ and 3c show zoomed parts with corrosion layers. On the basis of the SEM images we have estimated that the thickness of the embroidery threads is $0.6 \mathrm{~mm}$, the width of metal strip is $0.7 \mathrm{~mm}$, the metal strip thickness around $10 \mu \mathrm{m}$. The thickness of a silver layer can't be determined because the corrosion deteriorate it. The thickness of corrosion products is in the range 10 to $50 \mu \mathrm{m}$. All corrosion layers should be removed.
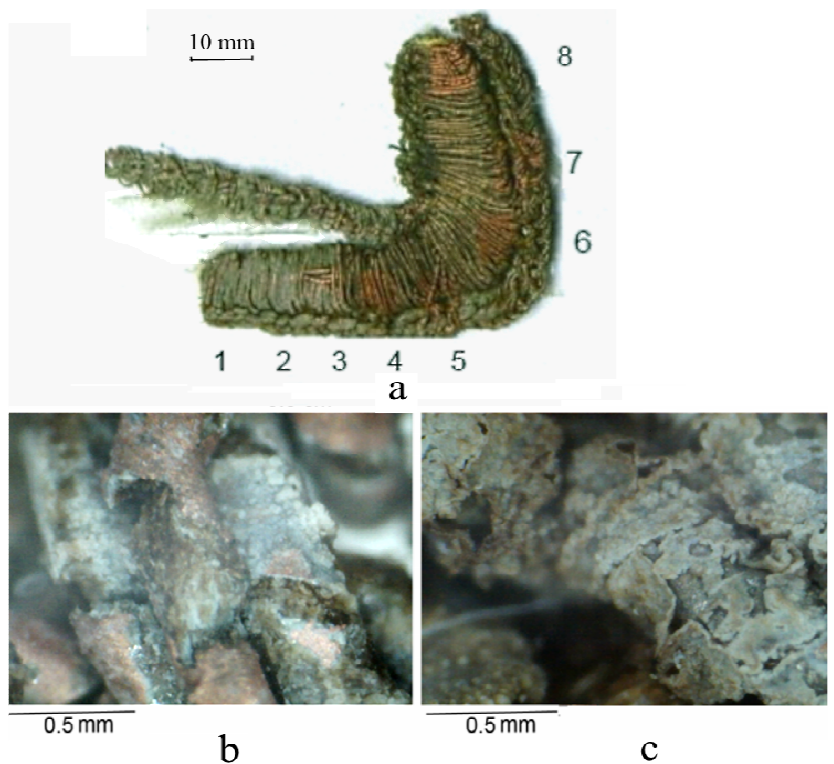

Fig. 3 a) Part of the shirt embroidery with laser cleaning zones, b) and c)

Zoomed parts with corrosiom layers 
Before cleaning the embroidery sample, the preliminary tests were made on $0.1 \mathrm{~mm}$ thick copper plate covered with a silver layer of $5 \mu \mathrm{m}$, in order to be determine the laser fluence that does not damage the silver layer. Trial tests are carried out with two wavelength (1064 and $532 \mathrm{~nm})$ and the number of pulses from 20 to 200. The fluence were ranged from 100-800 mJ/cm². Fig. 4 show SEM images of the irradiated surface zones with: $a-\lambda=1064 \mathrm{~nm}, \phi=100 \mathrm{~mJ} / \mathrm{cm}^{2}, \mathrm{~b}$ $\lambda=532 \mathrm{~nm}, \phi=200 \mathrm{~mJ} / \mathrm{cm}^{2}, \mathrm{c}-\lambda=1064 \mathrm{~nm}, \phi=300 \mathrm{~mJ} / \mathrm{cm}^{2}$ and $\mathrm{d}-\lambda=532 \mathrm{~nm}$, $\phi=375 \mathrm{~mJ} / \mathrm{cm}^{2}$. The damages, like detach silver layer are visible in the zones irradiated with fluence above $300 \mathrm{~mJ} / \mathrm{cm}^{2}$. Therefore, in the embroidery sample treatment the fluences below $300 \mathrm{~mJ} / \mathrm{cm}^{2}$ are used, except for one zone number 8 (Fig. 3).
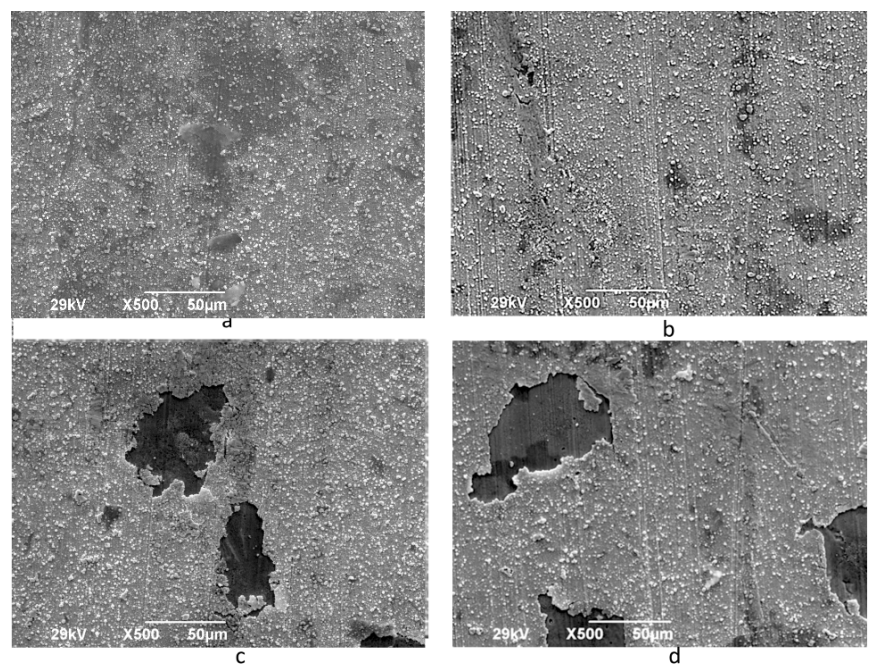

Fig. 4 SEM of irradiated zones on trial sample, silvered copper plate

\subsection{Optical microscopy}


The results of a laser beam-sample interaction were recorded with the optical USB Digital Microscope, Edmund Optics, with magnification 10X - 200X, progressive scan CMOS sensor, 6 LEDs and working distance $8.5-112.0 \mathrm{~mm}$.

The wavelength of $532 \mathrm{~nm}$ was used to expose the zones 1,2 and 3, and the fluence increased from 100 to $250 \mathrm{~mJ} / \mathrm{cm}^{2}$. The pulse number was the same for all three zones. It is obvious that the cleaning efficiency, increased with the increase of fluence (Figs. 6a-6e). Cleaning effects are visible in the central part of irradiated zones with an approximately diameter of $5 \mathrm{~mm}$, due to laser beam with the Gaussian energy distribution. Photo of zone 4 recorded with 200x magnification is presented in Fig $5 f$.

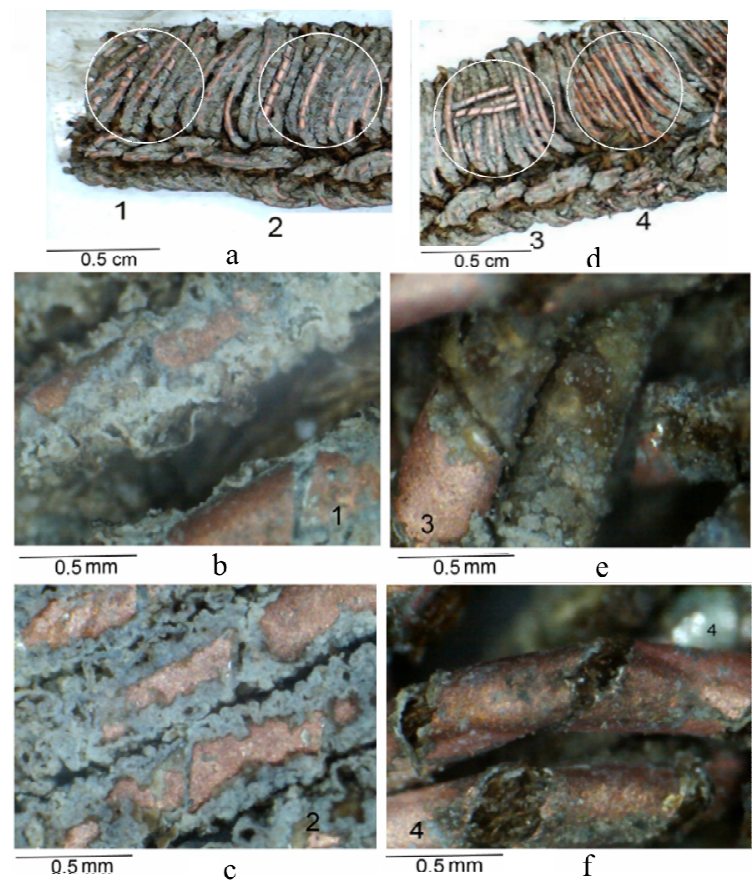

Fig. 5 The 1,2,3 and 4. Zones of cleaning shirt embroidery 
Comparison of zones 2 and 4 (Figs. 5) shows that cleaning is more efficient with the wavelength in the near infra-red area compared to the cleaning with the wavelength in the visible part of the spectrum $(523 \mathrm{~nm})$.

The laser beam with $1064 \mathrm{~nm}$ wavelength was used for zones 4 to 8 (Figs 5d, 5f, 6 and 7). The fluence for zones 4 (Fig. 5d and 5f) and 5 (Fig 6a-6c) was the same. The number of pulses was increased for zone 5, which resulted in more efficient removal of corrosion deposits on the metallic threads (Fig. 6b). On the cleaned surface, it can bee seen dark areas caused with further oxidation of the $\mathrm{Cu} 2 \mathrm{O}$ to $\mathrm{CuO}$. This phenomenon is difficult to avoid during laser corrosion cleaning because reduced input fluence reaches the copper surface which is below the corrosion product [28].

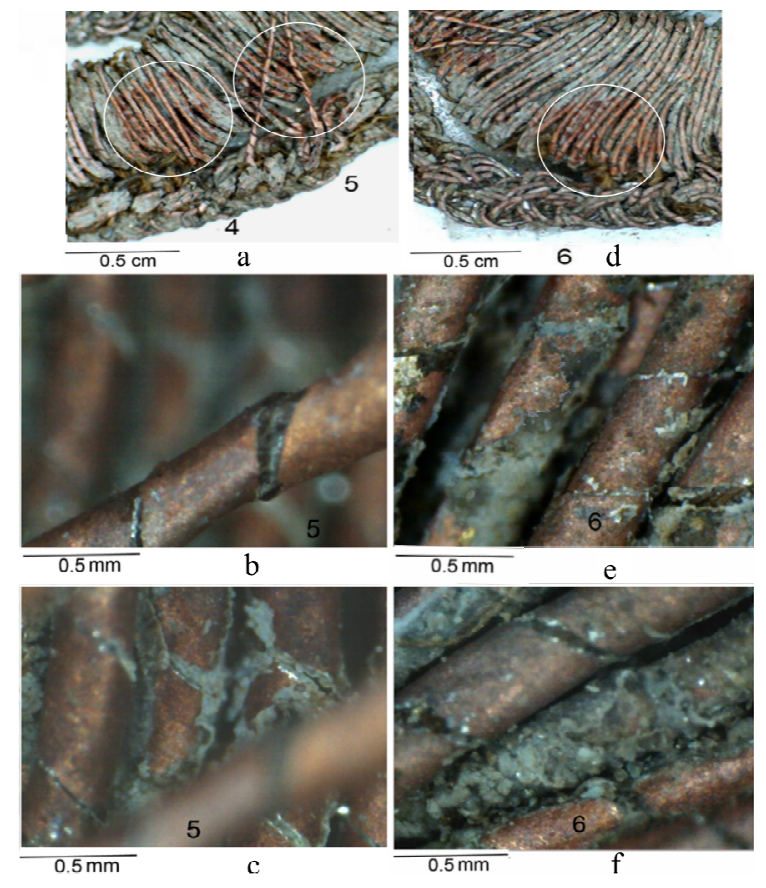

Fig. 6 Laser cleaning zones 5 and 6 
Zones 6-8 were irradiated with the same wavelength of $1064 \mathrm{~nm}$, the same number of pulses and fluence increasing from 200 (Figs 6 and 7) to $380 \mathrm{~mJ} / \mathrm{cm}^{2}$. The difference in the experimental conditions between zones 5 and 6 is the moisture percentage. The results show that, there was no significant improvement in cleaning, in the presence of water (zone 6), when lower energies were used. Only, the increase of fluence, in combination with the increased moisture, contributes to better cleaning effects, confirmed by the pictures of zone 8 (Fig. 7). On the other side, it is necessary to have insight on how much moisture can damage the textile parts of the sample (i.e. what is the stability of the fabric colour).

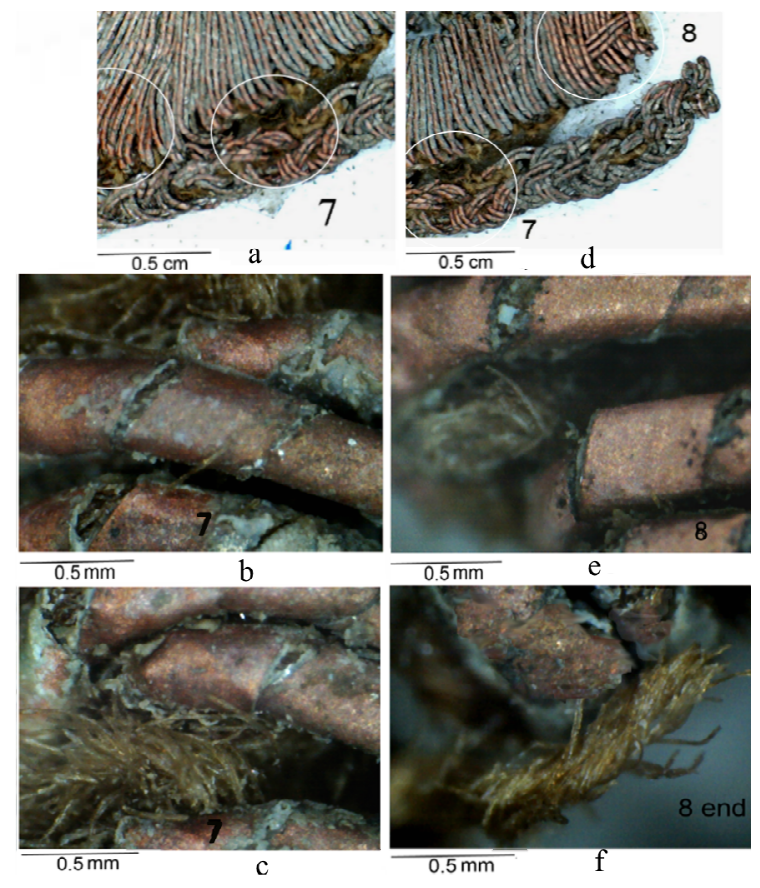

Fig. 8 Laser cleaning zones 7 and 8

The chosen parameters of corrosion product cleaning are below the damage threshold of metallic threads and textiles, becouse the aime was to 
determine the efficient cleaning threshold. The optimization of the procedure may be achieved by the change of the laser beam incidence angle in order to irradiate also the parts that are partially shielded.

As an illustration, the zone 5 (Fig. 6) is presented with two photographs (200x), taken at two different planes of the metallic embroidery on the shirt. It is obvious that the internal layers were not cleaned enough and that it is necessary to increase the number of pulses and change the beam incidence angle. A difference is visible between the plane where the laser beam was focused and the plane behind, where the fluence was lesser. Due to the absorption and dissipation the fluence was significantly reduced and the cleaning effects were poorer in the inner layers (Fig. 7).

Thermal effects on laser cleaned textile fibers such as fiber softening (melting), changing in shape and a sort of "welding" between fibers are not visible in a used range of energy and high number of pulses. A lot of cristals of corrosion products are spreaded on cotton fibers (Fig. 7).

\subsection{Image analysis}

For determination of the of cleaning degree, images obtained by optical microscopy were analysed and processed by Image-Pro Plus programme. Laser cleaning zones were marked and areas of copper and corrosion products are separated by different colour (Fig. 8) and automatically calculated their percent. Spaces between the threads were not considered. On figure 8 , some of investigated zones are shown. Beside zone 6, the part of analysed, uncleaned area is presented in fig $8 \mathrm{~b}$. Obtained results (table 2) show that the percentage of 
cleaned areas increase with fluence and wavelength. There is no significant difference between the percentage of cleaned areas when the wet or dry condition are used in combination with laser beams with the same fluence and wavelength of $1064 \mathrm{~nm}$.
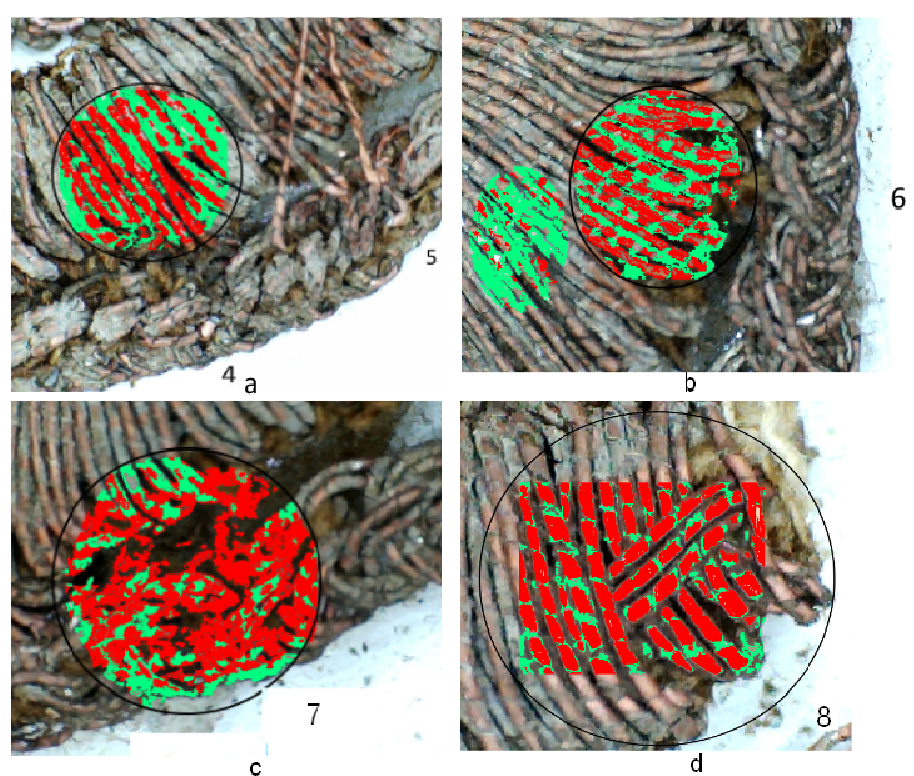

Fig. 8 Laser cleaned zones marked with Image Pro Plus programme

Table 2: Percentages of areas covered with corrosion product and cleaned ones in laser irradiated zones.

\begin{tabular}{|c|c|c|}
\hline zone & $\begin{array}{c}\text { Cleaned areas } \\
\%\end{array}$ & $\begin{array}{c}\text { Corroded areas } \\
\%\end{array}$ \\
\hline Uncleaned area & 12.3041 & 87.6959 \\
\hline 1 & 17.24798 & 82.75202 \\
\hline 2 & 23.81489 & 76.18511 \\
\hline 3 & 25.67812 & 74.32197 \\
\hline 4 & 47.11888 & 52.88112 \\
\hline 5 & 52.88075 & 47.11925 \\
\hline 6 & 53.55899 & 46.44101 \\
\hline 7 & 72.82868 & 27.17132 \\
\hline 8 & 79.63680 & 20.36321 \\
\hline
\end{tabular}

5.3 SEM and EDX analysis 
The metallic threads surface structures and morphology were monitored by an optical and by a scanning electron microscope. Microscopic tests, conducted by SEM, allow the study of the threshold of fluence that is save and efficient for corrosion product cleaning. The chemical analyses of cleaninged zones were made with the aim to determine the degree of cleaning, the composition of the corrosion products and the metallic threads. The figure 59 shows the SEM photographs of the zones 2 to 7 , and the spectra recorded in these zones on metal strips and cotton fibers by energy-dispersive spectroscopy (EDX). Spectras are determined as on the thread areas with corrosion products, so on areas without these products. Also spectrums are determined on the cotton fibre in the core of metal thread. In the zone 2, cleaned with wavelength of $532 \mathrm{~nm}$, spectra 4 shows presence of phosphorus. Spectra 2 on zone 5, cleaned with wavelength of $1064 \mathrm{~nm}$ and same number of pulses and fluence as zone 2, shows that there is not more phosphorus on the cotton fibre. Also, phosphorus is not found in the spectra 5 of zone 6 , whath confirm that phosphorus is eliminated as from metal part, so from organic fibre of metal thread, when the wavelength of $1064 \mathrm{~nm}$ is used.

In these study, laser cleaning is applied just on the part of embroidery without based cotton material. Part of the shirt embroidery was protected with paraloid B82. In this study there was used unprotected part of embroidery.

Laser cleaning with a wavelength of $532 \mathrm{~nm}$ has not been remuved phosphorus neither from the surface of the metal stripe nor from the surface of cotton fibers (spectra 4, zone 2). Areas cleaned by laser beam with a wavelength of 1024 are without phosphorus (spectra 2 and 5, from zones 5 and 6). 
As has been mentioned before, the copper threads were coated with silver, which was damaged to a great extent by corrosion. The EDX analysis (Table 3) shows that there is silver in the corrosion products but not on all metal surfaces. The phosphorus was registered in the spectra taken from the parts covered with residue corrosion products or textile threads around which were wrapped metal, copper threads. This means that the corrosion has progressed to such an extent that the silver layer has completely disappeared in some places and only the copper base of the thread remained. The presence of phosphorus was also evident in the corrosion products which also confirm the results of the previous tests and the conclusion that phosphine gas, used as a fumigant, has most probably accelerated the corrosion process on the shirt.

Table 3. EDX results, processing option: All elements analysed (Normalized) 

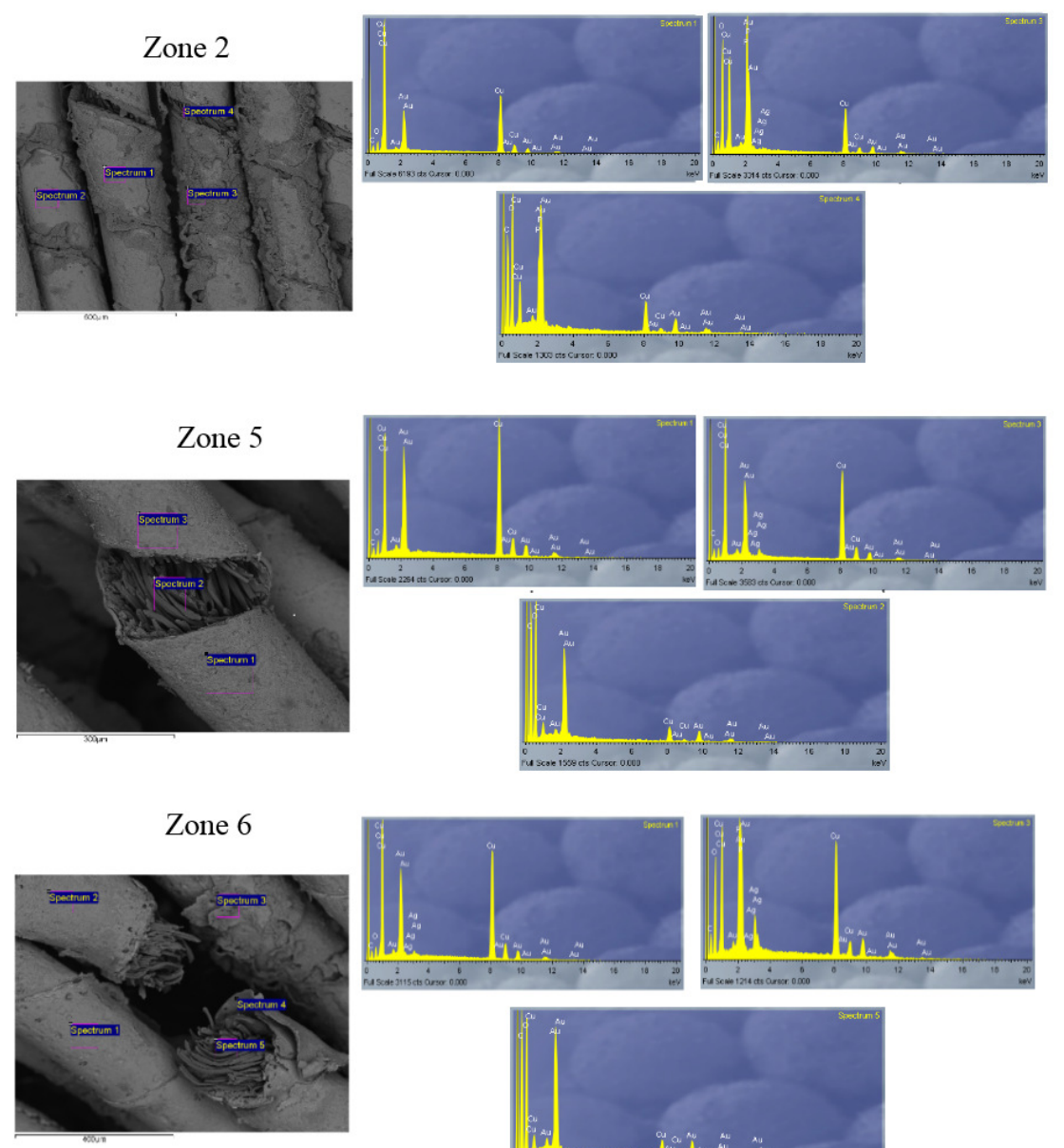

Zone 7
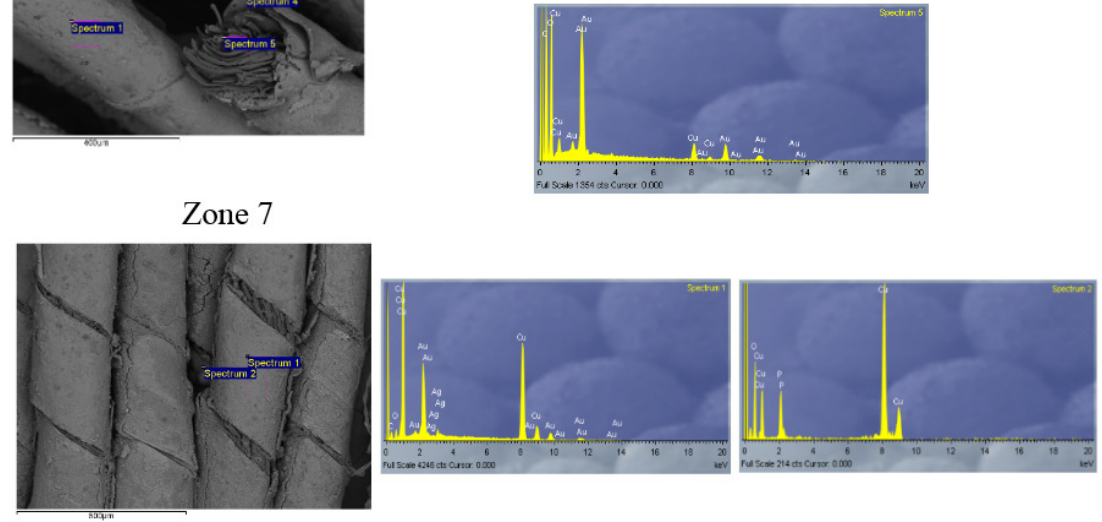

Fig. 9 SEM photo and EDX spectra for zones 2, 5, 6 and 7

The microscopic analyses performed on the corroded samples, before laser cleaning, show the presence of salt crystals in the most damaged parts. The greyish-black colour at some places can originate from the phosphide that did not react further. It is necessary to mention also, that the decomposition of copper phosphide is much slower than the decomposition of gold and silver phosphide. 
Information about the percentage of chemical elements contents, can lead to a conclusion about the occurring reactions type and its extent. These informations certainly helps in determining further testing and rehabilitation steps.

The results of microscopic analysis of metal threads before and after laser cleaning confirm that laser cleaning improves the surface of metal threads. The results show that there is a noticeable decrease of salt crystals and increase in the percentage of copper in the metal thread samples after laser cleaning. The laser cleaned surface retained more of the original topographical structure.

5.4 X-ray diffraction analysis

The samples of copper embroidery on the shirt were tested on a powder diffractometer PHILIPS PW 1710 under the following conditions: operating voltage: $U=40 \mathrm{kV}$, current intensity: $I=30 \mathrm{~mA}$, x-ray radiation from anticathode copper $(\mathrm{Cu})$, wavelength: $\mathrm{CuK} \alpha=0.154178 \mathrm{~nm}$, graphite monochromator, test range: $10-110^{\circ} 2 \theta$, step: $0.02^{\circ} 2 \theta$, time constant: 0,8 s per step.

The obtained data on the position of diffraction maximums $2 \theta\left(^{\circ}\right)$, the value of interplanar distances $d_{h k l}(\mathrm{~nm})$ for all $h k l$ reflections, as well as respective relative intensity $I / I_{\max }$ are presented graphically and in tables. Based on the obtained values of intensity $I / I_{\max }$ and interplanar distances $d$ and by comparing with the reference data and Joint Committee on Powder Diffraction Standards (JCPDS standards), present crystal phases were identified. 
Due to the nature of the samples it was not possible to make a perfectly flat and smooth surface on which the X-rays diffract and hence somewhat higher errors in $2 \theta$ measurement.

Only a single crystal phase was identified in the sample. This was copper that has a structure of most dense teseral packing. The Miller indices of individual reflections of this crystal phase are designated in Figure 10.

Experimentally determined parameters of a unit cell $a=0.36202(6) \mathrm{nm}$ show a slight increase $(\Delta a=0.0053 \mathrm{~nm})$ compared to $a_{\mathrm{Cu}}$ of pure copper $\left(a_{\mathrm{Cu}}=\right.$ $0.36149 \mathrm{~nm}$ ), which indicates that this is probably a copper alloy with a very small percentage of some other metal of greater radius.

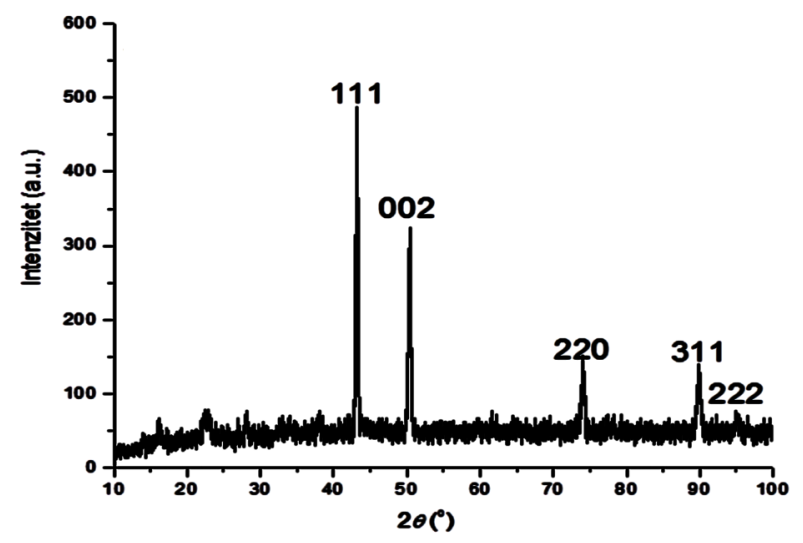

Fig. 10 XRD diagrams of the corrosion products, the Miller indices

From very weak and wide diffraction maximums on small $2 \theta$ angles it can be concluded that there is a small quantity in the sample of at least one other crystal phase or, which is more probable, several crystal phases. The value of interplanar distances $d$ indicates that these are probably hydrated chlorides, chlorates (atacamite, $\mathrm{Cu}_{2} \mathrm{Cl}(\mathrm{OH})_{3}$, JCPDS-78-372, ICSD-61252; Cu-chloride 
dehydrate, $\quad \mathrm{CuCl}_{2}\left(\mathrm{H}_{2} \mathrm{O}\right)_{2}, \quad$ JCPDS-88-1697, ICSD-40290; Cu-perchlorate hexahydrate, $\left(\mathrm{Cu}\left(\mathrm{H}_{2} \mathrm{O}\right)_{6}\right) \cdot\left(\mathrm{ClO}_{4}\right)_{2}$, JCPDS-79-728, ICSD-65683) and sulphates (brochantite, $\mathrm{CuSO}_{4} \cdot 3 \mathrm{Cu}(\mathrm{OH})_{6}, \quad \mathrm{JCPDS}-87-454$, ICSD-59288; chalcanthite, $\mathrm{CuSO}_{4} \cdot 5\left(\mathrm{H}_{2} \mathrm{O}\right)$, JCPDS-11-646, ICSD-4305) copper, which cannot be determined with certainty due to their very minimal presence and low degree of crystallinity.

\section{Conclusion}

The analysis of Nd:YAG laser cleaning of corrosion products on metallic threads of female shirt (Donja Brnjica, Kosovo and Metohija, Serbia, study collection of the Ethnographic Museum in Belgrade), showed that this method can help in resolving the long-lasting problem of appearance of corrosion on metallic embroidery textiles.

The basic goal was removing corrosion products and other deposits on the threads without applying classic methods. Some parameters for successful and safe cleaning of corrosion products on metallic threads were varied and results show that the safe laser fluences should not be higher than $250 \mathrm{~mJ} / \mathrm{cm}^{2}$ for all wavelengths and number of pulses between 100 and 300 depending on wavelengths (100 for $\lambda=1064 \mathrm{~nm}$ and 300 for $\lambda=532 \mathrm{~nm}$ ). The increasing of the number of pulses, and decreasing of the fluences, resulted in more efficient removal of corrosion deposits on the metallic threads. 
Comparison of different zones (Fig. 5,6 and 7) shows that cleaning is more efficient with the wavelength in the near infra-red, compared to the cleaning with the wavelength in the visible part of the spectrum $(523 \mathrm{~nm})$.

The chosen parameters of corrosion product cleaning are below the limit of damage of metallic threads and textile. The optimization of the procedure may be achieved by the change of the laser beam incidence angle in order to irradiate also the parts that are partially shielded.

The laser cleaning of museum object, with a complex structure and combination of different materials, has a lot of advantages, both in a qualitative and economic sense, especially for cleaning corroded metal threads in textile fabrics. The tests, analysed in this paper, confirmed that laser technology is environmentally more suitable then clasical chemical methods, becouse only generated wastes are the impurities ejected from the artwork's surface.

Obtained results may be useful as in conservation also for some metals in the industry. In the forthcoming period, it is necessary to study the aging process, change of colour and pigment on textile objects, the appearance of the recorrosion processes and other modifications that may occur after the implementation of laser cleaning in the process of conservation of textile objects with metallic threads.

\section{Acknowledgements}


This research was financially supported by the Ministry of Education, Science and Technological Development of Serbia under Projects TR-35046 and TR-34028. The authors especially thank the Ethnographic Museum in Belgrade, Serbia.

\section{References}

[1] C. Degrigny, E. Tanguy, R. Le Gall, V. Zafiropulos, G. Marakis, Laser cleaning of tarnished silver and copper threads in museum textiles, J. Cult. Herit. 4 (2003) 152s-156s.

[2] C. Frade, P. Cruz, E. Lopes, M. M. Sousa, J. Hall, R. Santos, A. AguiarRicardo, T. Casimiro, Cleaning classical Persian carpets with silk and precious metal thread: conservation and ethical considerations, in: J. Bridgland (Eds.), Proceedings of ICOM-CC $16^{\text {th }}$ Triennial Conference, Lisbon, September 19-23, 2011. [CD ROM]

[3] A. Timar-Balazsy, D. Eastop, Chemical Principles of Textile Conservation, Butterworth-Heinemann, Boston, Oxford, 1998.

[4] D. Radovanović, Degradation of metallic thread on textile objects at the Ethnographic Museum in Belgrade, Ethnographic Museum, Belgrade, 2008. (In Serbian).

[5] M. Sokhan, F. Hartog, D. McPhail, Surface Analysis of the Laser Cleaned Metal Threads, Lasers in the Conservation of Artworks LACONA V 
Proceedings, Osnabrück, Germany, Sept. 15-18, 2003, pp 237-244, DOI 10.1007/3-540-27176-7_29

[6] A. Elnaggar, P. Fitzsimons, A. Nevin, I. Osticioli, M. Ali, K. Watkins, Investigation of ultrafast picosecond laser system for cleaning of metal decorations of $17^{\text {th }}$ C. gloves of King Charles I, Investigation of Silk by Microscopy, e-Preservation Science (e-PS), 2015, 12, pp. 14-19, ISSN: $1854-$ 3928 print edition

[7] B . Taarnskov , P . Pouli and J . Bredal-Jørgensen, Lasers in the Conservation of Artworks VIII, Radvan et al. (eds), 2011 Taylor and Francis Group, London, Pages 67-73 Print ISBN: 978-0-415-58073-1, DOI: $10.1201 / \mathrm{b} 10567-12$

[8] B. Radojković, S. Ristić, S. Polić-Radovanović, Study of Ruby Laser Beam Interaction With Glass, FME Transactions 41 (2013) 109-113.

[9] S. Ristic, S. Polic-Radovanovic, B. Katavic, M. Kutin, Z. Nikolic, M. Puharic, Ruby laser beam interaction with ceramic and copper artifacts, J. Russ. Laser. Res. 31 (2010) 401-412.

[10] M. Speranza, M. Sanz, M. Oujja, A. De los Rios, J. Wierzchos, S. PérezOrtega, M. Castillejo, C. Ascaso, Nd-YAG laser irradiation damages to Verrucaria nigrescens, Int. Biodeter. Biodegr. 84 (2013) 281-290.

[11] S. Siano, J. Agresti, I. Cacciari, D. Ciofini, M. Mascalchi, I. Osticioli, A. A. Mencaglia, Laser cleaning in conservation of stone, metal, and painted artifacts: state of the art and new insights on the use of the Nd:YAG lasers, Appl. Phys. A-Mater. 106 (2012) 419-446. 
[12] R. Bordalo, P.J. Morais, H. Gouveia, C. Young, Laser Cleaning of Easel Paintings: An Overview, Laser Chem. (2006) Article ID 90279. 9 pages. doi:10.1155/2006/90279.

[13] H. Garbacz, E. Fortuna-Zalesna, J. Marczak, A. Koss, A. Zatorska, G.Z. Zukowska, T. Onyszczuk, K. J. Kurzydlowski, Effect of laser treatment on the surface of copper alloys, Appl. Surf. Sci. 257 (2011) 7369-7374.

[14] B. Katavić, S. Ristic, S. Polic-Radovanovic, Z. Nikolic, M. Puharic, M. Kutin, Analysis of the threshold of damage of copper and aluminium in interaction with Ruby laser, Chem. Ind. 64 (2010) 447-452.

[15] R. Pini, S. Siano, R. Salimbeni, M. Pasquinucci, M. Miccio, Tests of laser cleaning on archaeological metal artefacts, J. Cult. Herit. 1 (2000) S129S137.

[16] O. Abdel-Kareem, M. Harith, Evaluating the use of laser radiation in cleaning of copper embroidery threads on archaeological Egyptian textiles, Appl. Surf. Sci. 254 (2008) 5854-5860.

[17] F. Ferrero, F. Testore, Surface degradation of linen textiles induced by laser treatment: comparison with electron beam and heat source, AUTEX Research Journal, 2 (2002) 109-114.

[18] S. Ristić, S. Polić-Radovanović, B. Radojković, Laser cleaning of textile artefacts with corroded metal threads, in: Z. Anastasijevic (Eds.), Proceedings of the 6th international scientific conference, OTEH 2014, Belgrade, October 09-10, The Military Technical Institute, Belgrade, 2014, pp. 649-655. 
[19] J. Lee, J. Yu, Y. Koh,. Experimental study on the effect of wavelength in the laser cleaning of silver threads, J. Cult. Herit. 4 (2003) 157s-161s.

[20] I. Rezic, L. Ćurković, M. Ujevic, Simple methods for characterization of metals in historical textile threads, Talanta 82 (2010) 237-244.

[21]http://conferences.saxo.ku.dk/traditionaltextilecraft/keynote_speakers/present ations/Anna_Karatzani.pdf (May 26 $6^{\text {th }} 2015$ )

[22] E. J. Bond, T. Dumas, S. Hobbs, Corrosion of metals by the fumigant phosphine, J. Stored. Prod. Res. 20 (1984) 57-63.

[23] B. Gutarowska, A. Michalski, Microbial Degradation of Woven Fabrics and Protection Against Biodegradation, In: H.-Y. Jeon (Eds.), Woven Fabrics, InTech, Rijeka, Croatia, 2012, pp. 267-293. DOI: 10.5772/2594

[24] S. Polić-Radovanović, S. Ristić, B. Jegdić, Z. Nikolić, Methodological and technical aspects application of new technology to protect cultural heritage, Institut Gosa, Beograd, 2010. (In Serbian),.

[25] Lj. Petkovska, B. Radak, Results of emergency tests - analysis of the state of the process and causes of degradation of metal threads on textile objects at the Ethnographic Museum in Belgrade, Institute for nuclear sciences Vinča, Belgrade, 2000. (In Serbian).

[26] R. J. Brigham, Corrosive effects of phosphine, carbon dioxide, heat and humidity on electronic equipment: Phase II, Bonanza Printing \& Copying Centre Inc., Ottawa, ON, 1999.

[27] K. Gherdán, T. G. Weiszburg, Zs. Bendő, F. Kristály, T. Váczi, N. Zajzon, 2014 Phosphine fumigation damage: corrosion of metal and metal-textile 
composite museum objects. In: Proceedings of the $11^{\text {th }}$ international conference on non-destructive investigation and microanalysis for the diagnostics and conservation of cultural and environmental heritage, museo Arquelogico Nacional, Madrid, June 11-13, 2014. DOI: $10.13140 / 2.1 .2948 .5766$

[28] J. M. Lee and K. G. Watkins, Laser removal of oxides and particles from copper surfaces for microelectronic fabrication, Optics Express Special focus issue 7 (2000) 69-76. 